\title{
Effect of Two Educational Methods of Lecturing and Peer Group on Physical Activity among 12-15-Year-old Students in Health Promoting Schools
}

\author{
Atefeh Haghparast ${ }^{1}$, Camelia Rohani2,* (D) , ParvanehVasli³, Fatemeh Salmani ${ }^{4}$ and Milad Ahmadi Marzaleh ${ }^{5,6,7,8}$ \\ ${ }^{1}$ MSc in Community Health Nursing, Student Research Committee, School of Nursing and Midwifery, Shahid Beheshti University of Medical Sciences, Tehran, Iran \\ ${ }^{2} \mathrm{PhD}$, Associate Professor, Department of Community Health Nursing, School of Nursing and Midwifery, Shahid Beheshti University of Medical Sciences, Tehran, \\ Iran \\ ${ }^{3}$ PhD, Assistant Professor, Department of Community Health Nursing, School of Nursing and Midwifery, Shahid Beheshti University of Medical Sciences, Tehran, \\ Iran \\ ${ }^{4} \mathrm{PhD}$, Assistant Professor, Department of Epidemiology and Biostatistics, Faculty of Health, Birjand University of Medical Sciences, Birjand, Iran \\ ${ }^{5} \mathrm{PhD}$ in Disaster and Emergency Health, Student Research Committee, Department of Health in Disasters and Emergencies, Health Human Resources Research \\ Center, School of Management and Medical Informatics, Shiraz University of Medical Sciences, Shiraz, Iran \\ ${ }^{6}$ MPH in Health Policy, Health Policy Research Center, Institute of Health, Shiraz University of Medical Sciences, Fars, Iran \\ ${ }^{7}$ Research Center for Health Management of Mass Gathering, Red Crescent Society of the Islamic Republic of Iran, Tehran, Iran \\ ${ }^{8}$ Research Center for Emergency and Disaster Resilience, Red Crescent Society of the Islamic Republic of Iran, Tehran, Iran
}

* Corresponding author: Camelia Rohani, Department of Community Health Nursing, School of Nursing and Midwifery, Shahid Beheshti University of Medical Sciences, Tehran, Iran. Tel: +989122796907; Email: cameliarohani@yahoo.com

Received 2020 August 18; Revised 2020 September 01; Accepted 2020 September 10.

\begin{abstract}
Background: The promotion of physical activity among students is a matter of concern and one of Healthy People 2020 objectives. Objectives: The present study aimed to determine the effect of two educational methods of lecturing and the peer group on students' physical activity.

Methods: In this quasi-experimental study, 142 female students were randomly selected and assigned to two groups: lecture and peer group. Two physical activity questionnaires, namely the Physical Activity Questionnaire for Older Children and the International Physical Activity Questionnaire-Short Form, were filled out by the students before the educational intervention and eight weeks later. Data were analyzed in SPSS software(version 20) using the parametric (independent and paired sample t-tests) and non-parametric tests (ManWhitney U test and Wilcoxon Signed-Ranked test).

Results: The results of the study approved the following research hypothesis: "the two educational methods of lecture and peer group differently affect students' physical activity". In both groups, the level of physical activity was low at the commencement of the study. Nonetheless, eight weeks after the educational intervention program, a significant increase was observed in the physical activity of students in the peer group, compared to their counterparts in the lecture group using both questionnaires(P<0.001). Moreover, the number of students with low physical activity declined $(\mathrm{P}=0.001)$, while a substantial increase was observed in the number of students with moderate physical activity $(\mathrm{P}<0.01)$.

Conclusion: The dynamic nature of peer group causes sustainable learning in the domain of psychomotor skills. Therefore, this active teaching method should be developed in schools to arouse students' interest in health programs.

Keywords: Intervention study, Physical activity, School, Student
\end{abstract}

\section{Background}

Regular physical activity as one of the components of a healthy lifestyle(1) significantly contributes to the reduced risk of chronic diseases and premature mortality (2). Moreover, it can help to control weight, reduces the risk of cardiovascular disease, type II diabetes, and cancers, leads to healthy bones and muscles, and improves mental health $(3,4)$. Lack of regular physical activity is recognized as the fourth risk factor for mortality across the globe (5). Physical inactivity is responsible for around 250,000 annual number of premature deaths in the world.

The direct costs of the detections and treatment of physical inactivity-related diseases in the US and Canada are estimated to be 1.2 and 3.24 million dollars per year, respectively (6). Since physical activity habits develop during early childhood and persist into adulthood, the interest in exercise should be generated in children since the early years of life. Therefore, regular physical activity and health education in children and adolescents are considered one of the goals of Healthy People 2020 (7).

Apart from the prevention of diseases, physical activity in children and adolescents is effective in the reduction of stress, enhancement of self-esteem, discouragement of unhealthy entertainments and crime, the prevention of obesity and depression (8), and the improvement of physical fitness (9). According to the World Health Organization (WHO), physical activity is defined as every single body movement created by the musculoskeletal system and associated with energy consumption (10). Evidence shows that physical activity levels decrease 
during the course of life, especially in adolescence, and this decline is more pronounced among girls than boys (11).

In addition, the results of a study conducted by Dorrehet al. demonstrated that about $40 \%$ of high school and secondary school students exercise less than two hours a week (12). Along the same lines, the findings of a national survey indicated that $60 \%$ of Iranian students were not active, and their level of physical activity decreased with an increased level of education, and this decrease in girls was more pronounced than boys (13).

Although the Center for Disease Control and Prevention (CDC) recommends that all children should be active for at least 60 min every day, only $49 \%$ of boys and $35 \%$ of girls participate in physical activity (14). Numerous studies have pointed out that schools are a suitable place for the promotion of physical activity among children and teenagers (15). Moreover, health education in schools has a positive impact on a healthy lifestyle and promotes regular physical activity in students (16). A study on physical activity promotion in Iranian adolescents as a political document gave priority to the enhancement of quality and quantity of physical activity education among secondary and high school students (17).

Therefore, it seems that the implementation of educational interventions to promote physical activity is a health preference for students (18). Education through innovative techniques and in different classes in an appropriate atmosphere compatible with various circumstances has a significant impact on the enhancement of individuals' awareness, attitude change, and promotion of their behavior (16).

\section{Objectives}

In light of the aforementioned issues, the current study was conducted to test the following hypothesis: " two educational methods of lecture and peer group differently affect physical activity among 12-15-yearold female students'.

\section{Methods}

\subsection{Study Design}

This is a quasi-experimental study which was conducted at health-promoting schools in Qaemshahr, Mazandaran.

\subsection{Sampling and data collection}

A total of 142 female students aged 12-15 years were randomly selected from health-promoting schools. The required sample size was estimated considering the effect size of 0.5 , power of $80 \%$, the confidence of $95 \%$, and regarding a $10 \%$ sample attrition(19). For the purpose of the study, firstly, public female health-promoting schools in Qaemshahr were assigned to four clusters based on municipal districts. Thereafter, one health-promoting school was randomly selected from each cluster. Subsequently, seventh-grade students who were eligible (inclusion criteria: non-compliance with diet and medication, as well as physical and mental health status) were selected from four schools using a simple random sampling method. In the next stage, they were assigned to two groups, the lecture $(n=71)$ and the peer group $(n=71)$. In the current study, after obtaining necessary permissions and informed consent from all the students and their parents, data collection was performed using three questionnaires (demographic-health information and two physical activity questionnaires) before the intervention and two questionnaires (physical activity questionnaires) eight weeks after the intervention. The present study obtained all the necessary permissions from the university and educational department in Qaemshahr.

\subsection{Measurements}

Demographic-Health Information Questionnaire: This questionnaire included nine items regarding the demographic and health information of students and their parents, including student's age and Body Mass Index (BMI), parents' education, parents' employment status, previous education about regular physical activity, and doing planned physical activity or exercise prior to this study.

\subsection{Physical Activity Questionnaire for Older Children (PAQ-C)}

This 10-item 7-day recall instrument assesses general physical activity levels in children during the last seven days at school setting and out of it, from the fourth grade to eighth within the age range of 8-14 years (20). This questionnaire measures the frequency or repetition of activities performed during the last week in leisure time, sports courses, break time, lunchtime, in the evenings, after-school times, and holidays (20). The items are scored on a 5-point Likert scale ranging from 1-5 (low: 1.00-2.33; moderate: 2.34-3.66; high: 3.67-5.00) (21). The reliability of this instrument was confirmed in this study rendering a Cronbach's alpha coefficient of 0.88 .

\subsection{The International Physical Activity Questionnaire Short-Form (IPAQ-SF)}

This 7-item self-report questionnaire measures low, intermediate, and vigorous physical activity in terms of consumed energy and metabolism in minutes/weeks which was calculated based on standard protocols of scoring (22). It is based on the amount of metabolic equivalent for task (MET); thereafter, it is classified into three groups (low, moderate, and vigorous physical activity) (22). Low physical activity (0-599 MET-minutes/week), moderate physical activity( 600-300 MET-minutes/ 
week), and vigorous physical activity(>3000 METminute/week) (23).

In the present study, two different questionnaires were used to thoroughly assess the level of students' physical activity and cover the limitations of questionnaires measurement. The reliability of the IPAQ-Short-Form was calculated rendering a Cronbach's alpha coefficient of 0.76 .

\subsection{Designing the educational intervention}

Two different educational methods were used in two groups of students. In the lecture group, 71 students were allocated to four groups (17-18 students in each group), and each group received three 30-45 minute lecture sessions. In the peer group, 71 students were assigned to eight groups (89 students in each group). Five 45-60 minute dynamic group sessions were conducted once a week. Questionnaires were administered to both groups in two phases, before the educational intervention and eight weeks after the intervention. All students responded to the questions, and the process of data collection continued for four months.

The educational material for the three lecture sessions was provided after a review of the literature and an extensive search in reliable databases by the first author. The qualitative content validity of the educational material was evaluated by five faculty members who hold a PhD degree from the Nursing and Health Schools of the University. The main goal and objectives of education for each session were explained in this material. The necessary media were enclosed (three pamphlets and three booklets). For the peer group, apart from the same pamphlets and booklets, a special guide was prepared for each group session based on the literature review. The qualitative content validity of the guides was verified by the same faculty members and one faculty member in the field of psychiatric nursing and expert in group therapy.

In both groups, the first session was an introduction phase. The objectives of the research were explained, and a pre-test was conducted. Subsequently, the participants in the lecture group attended a lecture on the importance of regular daily physical activity, as well as the statistics reported in Iran and across the globe. These concepts were introduced in the peer group for discussion. The second and third sessions focus on "the barriers of regular exercise, the ways to overcome it", "the pyramid of physical activity, and the amount of necessary physical activity", respectively. In the peer group, the fourth and fifth sessions were centered on planning and evaluating a logical program for keeping a regular daily physical activity. All concepts in the lecture group were presented through lectures and in the peer group through group discussion. Eight weeks later, a post-test was administered in both groups.

\subsection{Data analysis}

Chi-Square $\left(\chi^{2}\right)$ and Fisher's exact test were used to compare the demographic characteristics of participants before the intervention. The ShapiroWilk test was utilized to assess the normal distribution of the main variables of the study (physical activity measurements by the PAQ-C and the IPAQ-Short-Form). Based on the results of the Shapiro-Wilk test, changes in the overall physical activity of the students were compared using independent and paired sample t-tests before and after the educational intervention (parametric tests). Nonetheless, changes in terms of students' physical activity levels (low, intermediate, vigorous) were compared using the Mann-Whitney $U$ test and Wilcoxon Signed-Ranked test (non-parametric tests). The data were analyzed in IBM SPSS software (version 20) (Armonk, NY: IBM Corp). A p-value less than 0.05 was considered statistically significant.

\section{Results}

\subsection{Demographic characteristics results}

The mean age scores of the students were reported as $13 \pm 1.05$ and $13 \pm 0.12$ years (range: $12-15$ years) in the lecture and peer groups, respectively. The mean scores of Body Mass Index (BMI) were obtained at $24.70 \pm 7.22$ and $23.27 \pm 3.44$ in the lecture and peer groups, respectively. The rest of the demographic characteristics of students and their parents are displayed in Table 1 . The results of the study indicated that variables of student's age (Man Whitney $\mathrm{U} ; \mathrm{P}=0.92)$ and BMI $\left(\chi^{2} ; \mathrm{p}=0.96\right)$ were homogeneous in both groups. Moreover, there was no difference between the lecture and peer groups regarding the variables of education and employment status of parents, sufficient family monthly income, previous education about exercise or regular physical activity, and doing exercise or scheduled physical activities within one week before the commencement of the study ( $\mathrm{P}$ 0.05; Table 1).

\subsection{Results for changes in the overall physical activity of students}

The study results verified the following hypothesis: "the two educational methods of lecture and peer group education differently affect the physical activity of students". Within-group differences using both questionnaires showed that there was no statistically significant difference in physical activity mean scores in the lecture group over time from baseline to eight weeks after the educational program $(\mathrm{P}>0.05)$. However, this change was significant in the peer group ( $\mathrm{P} \leq 0.001$; Table 2). Moreover, in both groups, the level of physical activity was low at the commencement of the study (pre-test or baseline phase; Table 2).

Nevertheless, between-group differences using both questionnaires demonstrated a statistically 
significant difference in the mean scores of students in the peer group, in comparison to their counterparts in the lecture group eight weeks after the educational intervention program $(\mathrm{P}<0.001$; Table 3). Before the educational program, there was no difference between the physical activity of students in two groups (P> 0.05; Table 3). After presenting three lectures to participants in the lecture group, their level of physical activity was increased; nonetheless, it was still low in this group (tables 2 and 3).

\subsection{Changes in the level of students' physical activity}

The distribution of students in terms of their physical activity levels (low, intermediate, vigorous) in the lecture and peer groups before and after the educational intervention program according to the PAQ-C and the IPAQ-Short Form is presented in Tables 4 and 5. Between-group comparison illustrated that the distribution of students in the peer group significantly decreased in the low level of physical activity as measured by the PAQ-C from baseline to eight weeks after the educational intervention $(\mathrm{P}=0.001)$.

On the other hand, the distribution of students in the peer group significantly increased in the intermediate level of physical activity measured by the PAQ-C from baseline to eight weeks after the educational intervention $(\mathrm{P}<0.001)$. As depicted in Table 5 , similar significant results were found by the IPAQ-Short-Form: a decrease in the low level of physical activity of students in the peer group, in comparison to the lecture group over time $(\mathrm{P}=0.001)$, and enhancement of the intermediate level of students' physical activity in the peer group, compared to the lecture group over time $(\mathrm{P}=0.002)$. The distribution of students in the peer group, in comparison to the lecture group, significantly increased in the vigorous level of physical activity as assessed by the PAQ-C after the educational intervention $(\mathrm{P}=0.001)$; however, it was not significant for the IPAQ-Short-Form $(\mathrm{P}=0.051)$.

Table 1. Demographic characteristics of 12-15-year-old students and their parents in two lecture (n=71) and peer groups ( $\mathrm{n}=71$ ) at health promoting schools

\begin{tabular}{|c|c|c|c|c|c|c|}
\hline \multirow{2}{*}{ Variables } & \multirow{2}{*}{ Categories } & \multicolumn{2}{|c|}{ Lecture Group (n=71) } & \multicolumn{2}{|c|}{ Peer Group (n=71) } & \multirow{2}{*}{ p value ${ }^{*}$} \\
\hline & & $\mathbf{N}$ & $\%$ & $\mathbf{N}$ & $\%$ & \\
\hline \multirow{3}{*}{ Father's Education } & High School & 35 & 49.0 & 32 & 45.1 & \multirow{3}{*}{0.861} \\
\hline & College & 22 & 31.0 & 23 & 32.4 & \\
\hline & University & 14 & 20.0 & 16 & 22.5 & \\
\hline \multirow{3}{*}{ Mother's Education } & High School & 40 & 56.3 & 42 & 59.0 & \multirow{3}{*}{0.438} \\
\hline & College & 21 & 29.6 & 22 & 31.0 & \\
\hline & University & 10 & 14.1 & 7 & 10.0 & \\
\hline \multirow{3}{*}{ Father's Employment Status } & Employed & 64 & 90.0 & 63 & 88.7 & \multirow{3}{*}{$0.712^{* *}$} \\
\hline & Retired & 5 & 7.0 & 4 & 5.7 & \\
\hline & Unemployed & 2 & 3.0 & 4 & 5.6 & \\
\hline \multirow{2}{*}{ Mother's Employment Status } & Employed & 23 & 32.3 & 17 & 23.9 & \multirow{2}{*}{0.629} \\
\hline & Housewife & 48 & 67.7 & 54 & 76.1 & \\
\hline \multirow{3}{*}{ Sufficient family monthly income } & Yes & 27 & 38.0 & 16 & 23.0 & \multirow{3}{*}{0.125} \\
\hline & No & 20 & 28.0 & 27 & 38.0 & \\
\hline & Somewhat & 24 & 34.0 & 28 & 39.0 & \\
\hline \multirow{2}{*}{$\begin{array}{l}\text { Previous education about exercise or regular } \\
\text { physical activity }\end{array}$} & Yes & 62 & 87.3 & 64 & 90.1 & \multirow{2}{*}{0.98} \\
\hline & No & 9 & 12.7 & 7 & 9.9 & \\
\hline \multirow{2}{*}{$\begin{array}{l}\text { Doing exercise or scheduled physical } \\
\text { activities within one week before the study }\end{array}$} & Yes & 6 & 8.5 & 8 & 11.3 & \multirow{2}{*}{0.573} \\
\hline & No & 65 & 91.5 & 63 & 88.7 & \\
\hline
\end{tabular}

${ }^{*}$ P-values are based on the Chi-Square $\left(\chi^{2}\right)$ and ${ }^{* *}$ Fisher exact test

Table 2. Comparison of the mean overall physical activity between the lecture $(n=71)$ and peer groups (n=71) using the Physical Activity Questionnaire for Older Children and IPAQ-Short-Form before and after the educational intervention

\begin{tabular}{|c|c|c|c|c|}
\hline Physical activity & Group & $\begin{array}{c}\text { Before } \\
\text { Mean (SD) }\end{array}$ & $\begin{array}{c}\text { After } \\
\text { Mean (SD) }\end{array}$ & P-value* \\
\hline PAQ-C & $\begin{array}{l}\text { Lecture Group } \\
\text { Peer Group }\end{array}$ & $\begin{array}{l}1.87(0.68) \\
2.01(0.85)\end{array}$ & $\begin{array}{l}1.91(0.57) \\
2.77(0.74)\end{array}$ & $\begin{array}{l}0.455 \\
0.001\end{array}$ \\
\hline IPAQ-Short Form & $\begin{array}{l}\text { Lecture Group } \\
\text { Peer Group }\end{array}$ & $\begin{array}{l}655.67(721.25) \\
866.17(892.25)\end{array}$ & $\begin{array}{c}804.05(857.21) \\
1514.83(1164.01)\end{array}$ & $\begin{array}{c}0.240 \\
<0.001\end{array}$ \\
\hline
\end{tabular}

* Within-group comparison before and after the educational intervention, p-values are based on the paired sample t-test

Table 3. Comparison of mean overall physical activity between the lecture $(n=71)$ and peer groups ( $n=71)$ using the Physical Activity Questionnaire for Older Children and IPAQ-Short Form before and after the educational intervention

\begin{tabular}{|c|c|c|c|c|c|}
\hline \multirow{2}{*}{ Physical activity } & \multirow{2}{*}{ Group } & Before intervention & \multirow{2}{*}{ P-value* } & After intervention & \multirow{2}{*}{ P-value* } \\
\hline & & Mean (SD) & & Mean (SD) & \\
\hline PAQ-C & $\begin{array}{l}\text { Lecture Group } \\
\text { Peer Group }\end{array}$ & $\begin{array}{l}1.87(0.68) \\
2.01(0.85)\end{array}$ & 0.271 & $\begin{array}{l}1.91(0.57) \\
2.77(0.74)\end{array}$ & $<0.001$ \\
\hline
\end{tabular}




\begin{tabular}{|c|c|c|c|c|c|c|}
\hline IPAC-Short Form & $\begin{array}{l}\text { Lecture Group } \\
\text { Peer Group }\end{array}$ & \multicolumn{2}{|c|}{$\begin{array}{l}655.67(721.25) \\
866.17(892.25) \\
\end{array}$} & 0.121 & $\begin{array}{c}804.05(857.21) \\
1514.83(1164.01) \\
\end{array}$ & $<0.001$ \\
\hline \multicolumn{7}{|c|}{ Between-group comparison before and after the educational intervention, $\mathrm{p}$-values are based on the independent sample t-test } \\
\hline \multicolumn{7}{|c|}{$\begin{array}{l}\text { Table 4. Distribution of students in terms of physical activity levels (low, intermediate, vigorous) using the Physical Activity } \\
\text { Questionnaire for Older Children before and after the educational intervention in the lecture }(n=71) \text { and peer groups }(n=71)\end{array}$} \\
\hline \multirow{2}{*}{ Physical activity* $^{*}$} & \multirow{2}{*}{$\begin{array}{c}\text { Intervention } \\
\text { phase }\end{array}$} & \multicolumn{2}{|c|}{ Lecture Group (n=71) } & \multicolumn{2}{|c|}{ Peer Group (n=71) } & \multirow{2}{*}{$\begin{array}{c}\text { P-value (Man } \\
\text { Whitney) }^{\mathrm{a}}\end{array}$} \\
\hline & & $\mathbf{N}$ & $(\%)$ & $\mathbf{N}$ & $(\%)$ & \\
\hline \multirow{2}{*}{ Low } & Before & 60 & 83.5 & 49 & 69.0 & 0.102 \\
\hline & After & 56 & 78.9 & 25 & 35.2 & 0.001 \\
\hline P-value (Wilcoxon) ${ }^{b}$ & & 0.217 & & & $<0.001$ & \\
\hline \multirow{3}{*}{$\begin{array}{l}\text { Intermediate } \\
\text { P-value (Wilcoxon) }\end{array}$} & Before & 10 & 14.1 & 16 & 22.5 & 0.035 \\
\hline & After & 14 & 19.7 & 34 & 47.9 & $<0.001$ \\
\hline & & 0.214 & & & 0.001 & \\
\hline \multirow{3}{*}{$\begin{array}{l}\text { Vigorous } \\
\text { P-value (Wilcoxon) }\end{array}$} & Before & 1 & 1.4 & 6 & 8.8 & 0.089 \\
\hline & After & 1 & 1.4 & 12 & 16.9 & 0.001 \\
\hline & & 0.688 & & & 0.002 & \\
\hline
\end{tabular}

${ }^{*}$ Classification of physical activity scores: (low: 1.00-2.33; moderate: 2.34-3.66; high: 3.67-5.00); aMan Whitney-U test was used for the comparison of changes in students' physical activity at each level of activity between the groups, bWilcoxon test was used for the comparison of changes in students' physical activity at each level of activity within the groups.

Table 5. Distribution of students in terms of physical activity levels (low, intermediate, vigorous) using the IPAC-Short Form before and after the educational intervention in the lecture $(n=71)$ and peer groups $(n=71)$

\begin{tabular}{|c|c|c|c|c|c|c|}
\hline \multirow{2}{*}{ Physical activity ${ }^{*}$} & \multirow{2}{*}{$\begin{array}{c}\text { Intervention } \\
\text { phase }\end{array}$} & \multicolumn{2}{|c|}{ Lecture Group } & \multicolumn{2}{|c|}{ Peer Group } & \multirow{2}{*}{$\begin{array}{c}\text { P-value (Man } \\
\text { Whitney) }\end{array}$} \\
\hline & & $\mathbf{N}$ & (\%) & $\mathbf{N}$ & $(\%)$ & \\
\hline \multirow{2}{*}{ Low } & Before & 45 & 63.4 & 42 & 59.2 & 0.253 \\
\hline & After & 42 & 59.2 & 13 & 18.3 & 0.001 \\
\hline P-value (Wilcoxon) ${ }^{b}$ & & 0.321 & & & $<0.001$ & \\
\hline \multirow{3}{*}{$\begin{array}{l}\text { Intermediate } \\
P \text { value (Wilcoxon) }\end{array}$} & Before & 25 & 35.2 & 27 & 38.0 & 0.065 \\
\hline & After & 23 & 32.4 & 48 & 67.7 & 0.002 \\
\hline & & 0.214 & & & 0.001 & \\
\hline \multirow{3}{*}{$\begin{array}{l}\text { Vigorous } \\
\text { p value (Wilcoxon) }\end{array}$} & Before & 1 & 1.4 & 2 & 2.8 & 0.089 \\
\hline & After & 6 & 8.5 & 10 & 14.1 & 0.051 \\
\hline & & 0.032 & & & 0.021 & \\
\hline
\end{tabular}

Classification of physical activity scores: low (0-599), intermediate (600-3000), and vigorous (> 3000); aMan Whitney-U test was used for

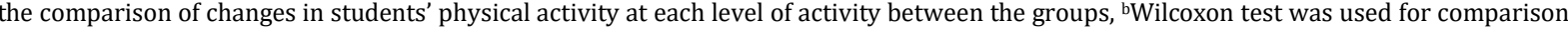
of changes in students' physical activity at each level of activity within the groups.

\section{Discussion}

In the current research, an educational intervention was conducted on 12-15-year-old female students to improve the physical activity of students at health-promoting schools in Qaemshahr. Two methods of lecture and peer group education were used in these educational programs. The results of the study pointed out that peer group educational intervention increased students' physical activity, while education through lectures did not show a significant effect on the promotion of students' physical activity. Consistent with previously conducted studies, one of the main findings of the present study was the low level of physical activity among the students at the commencement of the study (24-26).

A study showed that despite the benefits of regular physical activity in reducing the risk of cardiovascular disease, diabetes, colon cancer, osteoporosis, and depression, only $27 \%$ of students in grades 9-12 participated in moderate and vigorous physical activities (27). In a study on 394 girls and boys, Fisher et al. showed that $76.3 \%$ of subjects engaged in low levels of physical activity (28). Nonetheless, the results of another study on 400 Malaysian 13-yearold teenage girls and boys indicated that 35.5\%,
$61.5 \%$, and $3 \%$ of teenagers had low, moderate, and vigorous physical activity (21).

Based on previous studies, boys have higher levels of participation in physical activities in comparison to girls (29). The discrepancy between the findings of the current research and those reported by other studies can be attributed to different lifestyles adopted by girls, which is influenced by our culture. In addition, our research findings indicated that eight weeks after the education, the low level of physical activity persist among the students in the lecture group.

However, according to the results of the two questionnaires (i.e. PAQ-C and IPAQ-Short-Form), the number of students with low physical activity declined in the peer group, in comparison to their counterparts in the lecture group, while the number of students with moderate physical activity substantially increased. Nonetheless, these changes were more significant for students with low and moderate physical activity levels, compared to those with a vigorous level in the peer group.

These findings pointed to the superiority and effectiveness of active education in the peer group. Peer group education was attractive and influenced the physical activity of students since group dynamism worked well, compared to traditional 
education with regular lectures at schools. The results of a study on 84 male students in high school at Bavanat-Fars, Iran, revealed that educational interventions using the lecture method had no significant effect on the physical activity of male students (13).

In an interventional study on 300 male and female students in secondary schools in GachsaranKohgiluyeh and Boyer-Ahmad, Iran, the results showed that active learning-based educational planning increased students' physical activity in the intervention group, compared to the control group (23). Therefore, active teaching methods, along with educational planning, increased the stability of knowledge and satisfaction among students (23).

In the present study, the between-group comparison also revealed an interesting finding. In the lecture group, the mean sitting time decreased from $6.1 \pm 1.48 \mathrm{~h}$ to $5.83 \pm 1.17 \mathrm{~h}$, while in the peer group, it decreased from $7.01 \pm 1.69 \mathrm{~h}$ to $4.71 \pm 1.25 \mathrm{~h}$ in a two-month period (eight weeks) after the education. Although this decrease in time was significant in the peer group, it still needs special attention and planning. Studies show that sitting time, playing computer games, and watching television should be restricted to a maximum of two hours a day (29).

It can be argued that living in small apartments and space limitations at schools, on one hand, and the absence of the culture of using public places for sports activities are important factors encouraging students to spend more time sitting, playing computer games, and watching television (30). In a nutshell, studies quite similar to the present study were not found to compare the effect of two different educational methods of lecture and peer group on students' physical activity.

Nonetheless, previous studies which used the two mentioned educational methods independently in different populations indicated that replacement of lecture with active teaching methods, such as peer group education, reported more sustainable results in students' performance. For instance, the findings of a study on the impact of peer education method on knowledge, attitude, and practices of mothers regarding girls' health in puberty that peer education, compared to the lecture method, led to a substantial increase in the mean score of women's performance in terms of girls' health in puberty. Therefore, the mentioned study pointed to the advantage of this method over the lecture method (31).

In the same direction, Xiao and Zhao carried out a study to compare the effects of lecture practices and peer group education on levels of knowledge and attitude towards AIDS among Chinese students. The results of the referred study pointed to the profound effects of active learning and better performance in the peer group (32). Health promotion is one of the key roles of community health nurses who work as specialists at schools. In order to achieve health goals, these specialists should adopt teaching methods that are tailored to students' needs, abilities, and age (33).

Peer group education is one of the most effective approaches which bring about marked changes in students' healthy behaviors. Joining a peer group and tendency toward independence increase during adolescence; therefore, peers exert more influence than parents (34). Accordingly, peer group education is one of the effective strategies which can be adopted to change unhealthy behaviors. This education method involves all five senses, enhances thinking and creativity, and engage individuals in various stages of planning, implementation, and evaluation of programs (31).

Furthermore, peer group education provides golden opportunities for learning with dynamic group interactions and finally results in the development of health behaviors (34). One of the strengths of the current study lies in its design involving two groups and the simultaneous application of two different specific questionnaires for the evaluation of students' physical activity. Nonetheless, the use of self-report questionnaires has some limitations and underlines the accuracy of information. Moreover, factors affecting students' physical activities, such as cultural and family factors, could be regarded as the notable limitations of the present study.

From a general perspective, it can be concluded that physical inactivity is one of the major problems female students encounter in our community. Therefore, short and long-term strategic educational planning for the use of active teaching methods, especially peer group education at schools, by community health or school nurses can exert significant impacts on reducing the burden of chronic diseases and students' healthy lifestyles in healthpromoting schools.

\section{Conclusion}

The study results confirmed the research hypothesis "the educational methods of lecture and peer group education differently affect physical activity among 12-15-year-old female students. In this regard, peer group educational intervention increased students' physical activity, while education through lectures did not demonstrate a significant effect on the promotion of students' physical activity. It seems that the use of active teaching methods, such as peer education, due to the dynamics of peer group interaction causes sustainable learning in the students in the domain of psychomotor skills. Therefore, this active teaching method should be adopted to arouse students' interest in healthpromoting programs developed by schools or community health nurses. 


\section{Acknowledgements}

The authors' deepest appreciation goes to all students, their parents, and education officials of Qaemshahr, and the personnel of the School of Nursing and Midwifery of Shahid Beheshti University of Medical Sciences who helped us in conducting this research project.

\section{Footnotes}

Authors' Contribution: Atefeh Haghparast and Camelia Rohani were responsible for the study conception and design. Atefeh Haghparast performed data collection. Atefeh Haghparast, Camelia Rohani, ParvanehVasli, Fatemeh Salmani, and Milad Ahmadi Marzaleh performed the data analysis and made critical revisions to the paper for important intellectual content. This article was extracted from the first author's MSc thesis in Community Health Nursing from Shahid Beheshti University of Medical Sciences, School of Nursing and Midwifery. All authors read and approved the final version of the article.

Conflict of Interests: The authors declare that they have no conflict of interest regarding the publication of the current study.

Ethical Approval: The research ethical code of $301 / 9182$ was issued from the research ethics committee of the Shahid Beheshti University of Medical Sciences, School of Nursing and Midwifery in Tehran.

\section{Funding/Support: None.}

Informed consent: Written informed consent form was obtained from all participants included in the study.

\section{References}

1. Taymoori P, Niknami SH, Ghofranipour F. Effects of a schoolbased intervention on the basis of Pender's health promotion model to improve physical activity among high school girls. J Armaghan Danesh. 2008;12(2):46-59.

2. Wolin K, Heil DP, Matthews CE, Askews S, Benneff GG Validation of the international physical activity questionnaireshort among blacks. J Phys Act Health. 2008;5(5):746-60. doi: 10.1123/jpah.5.5.746. [PubMed: 18820348].

3. Bates H. Daily physical activity for children and youth: a review and synthesis of the literature. Canada: Canadian Fitness and Lifestyle Research Institute; 2006.

4. Physical activity and health the benefits of physical activity. Center for Disease Control and Prevention (CDC). Available at: URL: http://www.cdc.gov/physicalactivity/everyone/ health; 2019.

5. World Health Organization. Global strategy on diet, physical activity and health. Geneva: World Health Organization; 2019.

6. Allison KR, Adlaf EM, Dwyer JJM, Lysy DC, Irving HM. The decline in physical activity among adolescent student. Can J Public Health. 2007;98(2):97-100. doi: 10.1007/BF03404317.

7. Park H, Kim N. Predicting factors of physical activity in adolescents: a systematic review. Asian Nurs Res. 2008; 2(2):113-28. doi: 10.1016/S1976-1317(08)60035-3. [PubMed: 25031244].

8. Taymoori P, Niknami SH, Ghofranipour F. Cognitive and psychosocial factors of physical activities among adolescents in Sanandaj by framework of Pender's health promotion and stage of change models. J Kermanshah Univ Med Sci. 2008; 11(4):393-406.

9. Kazemi A, Eftekhar-Ardabili H, Nekuei-Zahraei N. Pattern of physical activity and the promoters among adolescent girls of Isfahan. J Ghazvin Univ Med Sci. 2012;15(1):40-7.

10. Physical activity. World Health Organization. Available at: URL: http://www.who.int/topics/physical- activity/en/; 2019.

11. Dumith S, Gigante DP, Domingues MR, Kohl HW. Physical activity changes during adolescence: a systematic review and a pooled analysis. Int J Epidemiol. 2011;40(3):685-98. doi: 10.1093/ije/dyq272. [PubMed: 21245072].

12. Kelishadi R, Kahbazi M, Rabiei K, Heidari S, Doreh F, Baghaie A. Physical activity level among children of Markazi and Isfahan Provinces (2000). Arak Med Univ J. 2004;7(1):26-33.

13. Ghaffari M, Sharifirad G, Malekmakan E, Hassanzadeh A. Effect of educational intervention on knowledge, attitude, and behavior about physical activity among grade 1 students of male high schools in Bavanat, Iran. J Health Syst Res. 2012;7(6):965-76.

14. Dunn LL, Venturanza JA, Walsh RJ, Nonas CA. An observational evaluation of move to improve, a classroom based physical activity program, New York City Schools, 2010. Prev Chronic Dis. 2012;9:E146. doi: 10.5888/pcd9.120072. [PubMed: 22974754].

15. Sutherland R, Campbell E, Lubans DR, Morgan PJ, Okely AD, Nathan $\mathrm{N}$, et al. A cluster randomized trial of a school-based intervention to prevent decline in adolescent physical activity levels: study protocol for the physical activity 4 everyone trial. BMC Public Health. 2013;13:57. doi: 10.1186/1471-2458-1357. [PubMed: 23336603].

16. Ahmadi Tabatabaei SV, Taghdisi MH, Sadeghi A, Nakhaei N, Balali F. The effect of education in physical activities on knowledge, attitude and behavior of Kerman health center's staff. J Res Health. 2012;2(1):55-62.

17. Mounesan L, Sepidarkish M, Hosseini H, Ahmadi A, Ardalan G, Kelishadi R, et al. Policy brief for promoting physical activity among Iranian adolescents. J Isfahan Med Sch. 2013 31(233):510-20.

18. Parhoodeh Y, Khezeli M, Bakhtiyari M, Delpisheh A, Latifi A. Effects of education based on Transtheoretical model on physical activity of college students. Health Syst Res. 2012;8(2):320-9.

19. Plichta SP, Kelvin EA. Munro's statistical method for health care research. $6^{\text {th }}$ ed. Philadelphia: Lippincott Williams \& Wilkins; 2013.

20. Kowalski KC, Crocker PR, Donen RM. The physical activity questionnaire for older children (PAQ-C) and adolescent (PAQ-A) manual. College Kinesiol Univ Saskatchewan. 2004; 87(1):1-38.

21. Dan SP Jr, Mohd Nasir MT, Zalilah MS. Sex and ethnic differentials in physical activity levels of adolescents in Kuantan. Malay J Nutr. 2007;13(2):109-20. [PubMed: 22691749].

22. Guidelines for data processing and analysis of the physical activity questionnaire short and long form revised. International Physical Activity Questionnaire. Available at: URL: http://www.ipaq.ki.se/scoring; 2005.

23. Solhi M, Zinatmotlagh F, Karimzade Shirazi K, Taghdisi $\mathrm{MH}$ Jalilian F. Designing and implementing educational programs to promote physical activity among students: an application of the theory of planned behavior. Ofogh-E-Danesh. 2012; 18(1):45-52.

24. Oh JW, Lee EY, Lim JJ, Lee SH, Jin YS, Song BK, et al. Result from South Koreas 2018 report card on physical activity for children and youth. J Exerc Sci Fit. 2019;17(1):26-33. doi: 10.1016/j. jesf.2018.10.006. [PubMed: 30662511].

25. Huang WY, Wong SH, Sit CH, Wong MC, Sum RK, Wong SW, et al. Result from Hong Kong 2018 report card on physical activity for children and youth. J Exerc Sci Fit. 2019;17(1):149. doi: 10.1016/j.jesf.2018.10.003. [PubMed: 30662509].

26. Wu CL, Chang CK. Result from the Chinese Taipei (Taiwan) 2018 report card on physical activity for children and youth. J Exerc Sci Fit. 2019;17(1):8-13. doi: 10.1016/j.jesf.2018.10.005. 
[PubMed: 30662508].

27. Kahn EB, Ramsey LT, Brownson RC, Heath GW, Howze EH, Powell KE, et al. The effectiveness of interventions to increase physical activity: a systematic review. Am J Prev Med. 2002;22(4):73-107. doi: 10.1016/S0749-3797(02)00434-8.

28. Fisher A, Reilly JJ, Kelly LA, Montgomery C, Williamson A Paton JY, et al. Fundamental movement skills and habitual physical activity in young children. Med Sci Sports Exerc. 2005;37(4):684-8. doi: 10.1249/01.mss.0000159138.48107. 7d. [PubMed: 15809570].

29. Kelishadi R, Rabie K, Khosravi A, Famouri F, Sadeghi M, Shirani SH. Assessment of physical activity of adolescents in Isfahan. Shahrekord Univ Med Sci. 2001;3(2):55-66.

30. Ziaee V, Kelishadi R, Ardalan G, Gheiratmand R, Majdzadeh SR,
Monazzam MM. Physical activity in Iranian students CASPIAN Study. Iran J Pediatr. 2006;16(2):157-64.

31. Sistani M, Khoi M, Taghdisi MH. Promoting knowledge, attitude and practices (KAP) of the mothers in their girls' pubertal health based on peer education approach. J Babol Univ Med Sci. 2010;11(6):33-9.

32. Xiao N, Zhao H. Effects of lectures and peer education on knowledge and attitude about AIDS among students of college of science and engineers. Chin J Health Educ. 2004;20(5):402-5.

33. Stanhope M, Lancaster J. Community and public health nursing. $6^{\text {th }}$ ed. St. Louis, USA: Mosby Company; 2016.

34. Parvizi S, Ahmadi F. Adolescence health and friendships: a qualitative study. FEYZ J Kashan Univ Med Sci. 2007;10 (4): 46-51. 